\section{A rare cause of upper}

\section{gastrointestinal bleeding}

A 49-year-old woman with chronic obstructive pulmonary disease, Barrett's esophagus and type 2 diabetes who was taking singledose ASA daily and had recently undergone cholecystectomy presented to the emergency department with sudden onset of massive hematemesis and shock. After aggressive resuscitation, she underwent emergent upper gastrointestinal endoscopy. The bulb and descending duodenum appeared normal. The stomach was full of fresh blood and clot that had to be cleared. The body and antrum showed moderate erosive gastritis. Close inspection of the lesser curvature near the cardia revealed a small clot and a visible vessel within a tiny mucosal defect surrounded by normal mucosa (Fig. I); there was no active bleeding. The characteristics of the lesion and the typical location led to a diagnosis of Dieulafoy's lesion. The lesion and surrounding tissue were injected with epinephrine. Repeat endoscopy at I week showed partial healing, and the patient was discharged in good condition with a prescription

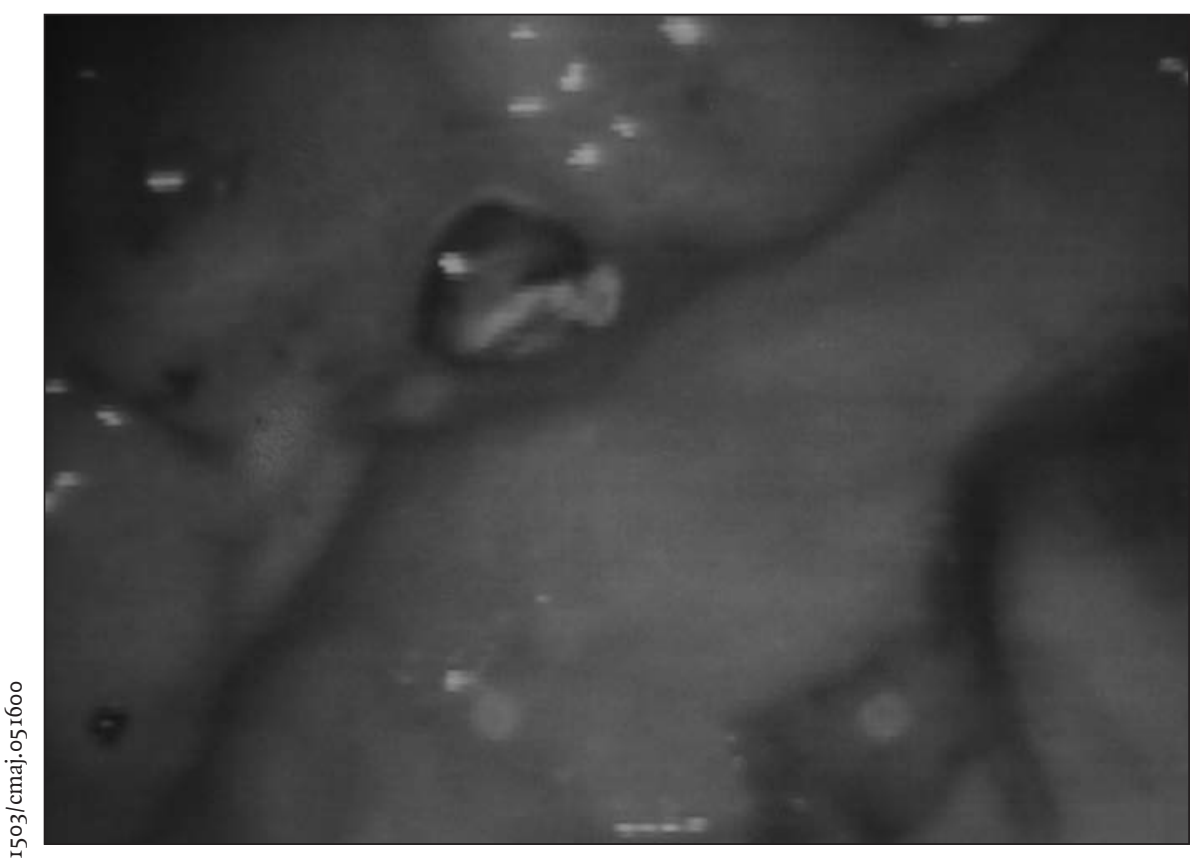

Fig. 1: Dieulafoy's lesion seen on lesser curvature of stomach. for oral therapy with a proton pump inhibitor. Endoscopy at 6 months revealed complete healing.

Dieulafoy's lesion arises from an enlarged submucosal artery that runs too close to the gastrointestinal mucosa. The pathophysiology is not well understood but may involve erosion of the mucosa by pressure from the artery and subsequent rupture of the vessel. Dieulafoy's lesion is responsible for about $2 \%$ of acute upper gastrointestinal bleeds (Table I). ${ }^{1-3}$ This anomaly may develop anywhere in the gastrointestinal tract, but it usually occurs in the proximal stomach, often on the lesser curvature within $6 \mathrm{~cm}$ of the gastroesophageal junction. ${ }^{2,3}$ This may be because the lesser curvature is not perfused by a submucosal plexus but rather derives its blood supply directly from tributaries of the right and left gastric arteries.

A patient with Dieulafoy's lesion usually presents with acute massive upper gastrointestinal bleeding; the median age at presentation is in the sixth decade. The prevalence of asymptomatic lesions is unknown. Anemia is rare. Comorbidities, especially cardiac and pulmonary disease, are common. ${ }^{2,3}$ Some have suggested an association with pep-

\begin{tabular}{lc}
$\begin{array}{l}\text { Table 1: Causes of acute upper } \\
\text { gastrointestinal bleeding* }\end{array}$ \\
\hline Cause & Frequency, \% \\
\hline Peptic ulcer & $35-50$ \\
Esophagitis & $20-30$ \\
\hline $\begin{array}{l}\text { Erosive gastritis/ } \\
\text { duodenitis }\end{array}$ & $10-20$ \\
$\begin{array}{l}\text { Esophagogastric varices } \\
\text { Mallory-Weiss syndrome }\end{array}$ & $5-12$ \\
Neoplasm & $2-5$ \\
\hline $\begin{array}{l}\text { Vascular cause, } \\
\text { including Dieulafoy's lesion }\end{array}$ & $2-5$ \\
\hline
\end{tabular}

"Modified, with permission, from Palmer ${ }^{1}$ Postgrad Med J 2004;80:399-404. @ 2004 BMJ Publishing Group.

tic ulcer disease and mucosal irritants such as NSAIDs and alcohol; however, the role of these factors in the pathogenesis of Dieulafoy's lesion and the risk of hemorrhage remains to be defined.

Diagnosis is often difficult owing to the lesion's small size and the intermittent nature of the bleeding. Dieulafoy's lesion should be suspected if there is persistent hemorrhage of unknown origin. Historically, surgical treatment was associated with high morbidity and mortality; however, the advent of therapeutic endoscopy has revolutionized diagnosis and treatment and dramatically improved outcomes. The rate of initial endoscopic diagnosis and the rate of permanent hemostasis are both over $90 \% .^{2}$ Injection sclerotherapy, thermal probes, cautery, laser, rubberband ligation and clips have all been used successfully. ${ }^{2,3}$ Recurrent bleeding after treatment is rare. ${ }^{2}$

\section{George Rakovich}

Department of Surgery

Brome-Missisquoi-Perkins Hospital Cowansville, Que.

Competing interests: None declared.

\section{REFERENCES}

I. Palmer K. Management of haematemesis and melaena [review]. Postgrad Med J 2004;80(945): 399-404.

2. Yilmaz M, Ozutemiz O, Karasu Z, et al. Endoscopic injection therapy of bleeding Dieulafoy lesion of the stomach. Hepatogastroenterology 2005;52 (65):1622-5.

3. Schmulewitz N, Baillie J. Dieulafoy lesions: a review of 6 years of experience at a tertiary referral center. Am J Gastroenterol 2001;96(6):I688-94. 